\title{
Independent Research and Development or Technology Mergers and Acquisitions? Decision Mechanisms of Research and Development Strategies in a Two-Stage Game
}

\author{
Fenglian Wang $\mathbb{D},{ }^{1}$ Zongming Zhang $\mathbb{D}^{2}$, and Hua Zhao $\mathbb{D}^{2}$ \\ ${ }^{1}$ School of Economics and Management, Anhui Polytechnic University, Wuhu 241000, Anhui, China \\ ${ }^{2}$ School of Economics and Business Administration, Chongqing University, Chongqing 40030, China \\ Correspondence should be addressed to Zongming Zhang; 20120201049@cqu.edu.cn
}

Received 10 June 2021; Revised 11 August 2021; Accepted 21 August 2021; Published 1 September 2021

Academic Editor: Ricardo López-Ruiz

Copyright ( $\odot 2021$ Fenglian Wang et al. This is an open access article distributed under the Creative Commons Attribution License, which permits unrestricted use, distribution, and reproduction in any medium, provided the original work is properly cited.

\begin{abstract}
This research introduces the three variables of spillover effect, research and development efficiency, and cost of mergers and acquisitions as the chief factors affecting independent research and development and technology mergers and acquisitions based on a two-stage game theory model of research and development strategies. Using these three variables, this research explains the selection of independent research and development or technology mergers and acquisitions according to profit maximization. Based on the theory model, this research finds that costs of mergers and acquisitions and spillover effects play a significant role in research and development decisions. In addition, excessive costs of mergers and acquisitions can increase research and development expenditures, therefore reducing profit and affecting the organizational operation and development. Therefore, when the costs of mergers and acquisitions exceed a certain level, companies will abandon technology mergers and acquisitions and choose independent research and development; and a higher knowledge spillover effect reduces the costs of independent research and development, therefore increasing profit. In conclusion, given certain costs of mergers and acquisitions, a higher spillover effect helps business organizations to choose independent research and development strategies.
\end{abstract}

\section{Introduction}

Technical progress and technology mergers and acquisitions are significant sources of technology progress and value realization, which lead to improving corporate innovation capabilities and competitiveness [1]. Technology mergers and acquisitions are activities aimed at acquiring the target's technical resources. After the technology merger, the acquirer obtains control of the target and can reintegrate the target's technical resources, the most thorough form of technology transfer, according to the corporate development strategy. Mergers and acquisitions transform technical resources outside the organization into internal resources. World-renowned high-tech companies such as Microsoft, Apple, Samsung, Huawei, and Alibaba are typical representatives of independent research and development. For example, Alibaba has invested in greenfield and has become the first domestic technology company to reach the standard of the national green data center. These high-tech companies assist the development of cutting-edge technology in diverse fields with their financial and human capital. In the future, technology advances such as artificial intelligence, the internet of things, driverless cars, energy-saving and environmental protection technology, unmanned management, and smart homes will enable far-reaching changes. As globalization and the internet have transformed communication channels, the market for technical information has opened up on a global scale, altered business models to create value, transformed the relationship between enterprises, and shifted the paradigm of enterprise technology innovation from closed to open. However, independent research and development alone can no longer meet the 
rapid changes in technology; therefore, technology mergers and acquisitions have become the inevitable choice for business development and competitiveness.

According to Boston Consulting Group's 2017 technology takeover report, the total value of global technology mergers and acquisitions transactions was more than US\$700 billion in 2016. Furthermore, one in five transactions is directly related to technology mergers and acquisitions.

Both independent research and development and technology mergers and acquisitions have long been recognized as strategies to drive economic growth [2]. It is not surprising that the decisions of research and development strategies are given considerable attention in both theory and practice because they are key to business survival, improving the industrial structure of China, and even ensuring the sustainability and development of the market economy [3]. However, there are many considerations when choosing a research and development model. For example, companies not only need to invest in research and development but also face enormous risks when conducting technology research and development. For diverse technology innovation activities, companies frequently have diverse requirements in terms of resource input and return on investment, especially facing a coordination problem between independent research and development and technology mergers and acquisitions [4]. Choosing research and development strategies on the road to development remains a major and complex issue that many companies currently face. Most of the extant literature discusses enterprise research and development investment decisions, but a few scholars compare how diverse research and development models affect the realization of corporate profit maximization goals and how to choose research and development strategies in diverse situations. Consequently, it is imperative to explore the decision-making mechanism of independent research and development and technology mergers and acquisitions.

Research on research and development strategies has always been prominent in the field of economics and management. Current research principally concerns the impact of both technology mergers and acquisitions and independent research and development on business performance and innovation performance. For example, Cortés et al. [5] concluded that industrial productivity could still promote cross-border mergers and acquisitions despite the adverse effects of capital productivity in Latin America between 1996 and 2010. In addition, Hau [6] investigated the influence of the technology introduction networks on the import substitution of small and medium-sized risk enterprises and discussed the regulating function of research and development centers. In a re-examination of the relationship between mergers and acquisitions and postacquisition innovation performance, Zhao et al. [7] found that a higher level of research and development investment can lead to better technology absorption. He et al. [8] analyzed panel data from 22 Chinese manufacturing industries from 2000 to 2015 to examine the relationship between the international competitiveness of the industry and its capacity to innovate independently, finding that Chinese companies participating in the international market are increasingly relying on independent innovation. Wei et al. [9] analyzed six crossborder mergers and acquisitions using multiple case study methods, transforming the inferiority of the source country into a system and product dimension and proposing a proper strategy for companies in emerging economies. To analyze the relationship between collaborative innovation and corporate innovation performance, Cao et al. [10] applied the nonlinear panel threshold regression model. In all, the previous studies have illustrated the importance of technology introduction and independent innovation to the development of companies and regional economies.

Presently, research on the research and development strategies of independent research and development and technology mergers and acquisitions is plentiful. For example, according to $\mathrm{Li}$ and $\mathrm{Wu}$ [11], when they accounted for three types of technology knowledge acquisition (internal research and development, introduction of foreign technology, and purchase of domestic technology), their findings determined that the relative importance of the three types of technology knowledge varied dramatically based on industry. In a study by Kang et al. [12], technology acquisition has an inverted U-shaped relationship to innovation performance, suggesting that it is a double-edged sword in terms of internal research and development. Bai and Tan [13] used data from passenger car companies from 1998 to 2007 and proposed that independent research and development are more beneficial to increasing the number of patents than technology mergers and acquisitions. Wang and Han [14] selected Chinese provincial data from 2003 to 2012 to explore the impact of independent research and development and technology mergers and acquisitions on energy intensity. From 2001 to 2015, Du et al. [15] empirically tested and analyzed data from large and medium-sized enterprises in 36 industrial industries in China. Under the background of industrial upgrading, they investigated the relationship between independent research and development and the introduction of external technology by companies. The results showed the improvement of operating performance is inseparable from the introduction of technology and independent research and development and that there is a certain degree of substitution and complementarity between the latter two concepts. Liu and Liu [16] measured the domestic technology level and the vertical specialization index of China's manufacturing industry and its 16 subindustries from 1992 to 2012. The findings showed that both indicators have been continuously improving, therefore illustrating how the manufacturing industry is in a trend of deep integration into the vertical specialization of labor by examining the impact of domestic technology. Observing 215 acquisitions of Chinese listed pharmaceutical companies from 2012 to 2016, Yue et al. [17] found that research and development negatively impact acquisition performance, confirming that the acquisition motive modifies the relationship between research and development and acquisition performance. Zhang and Sun [18] studied how high-tech companies choose between independent research and development and technology mergers and 
acquisitions, as well as the effects of the three elements of competitive dynamics on evolving innovative behavior and competitive results. Using the intensity of intellectual property transactions as the threshold variable based on the threshold model, Yang [2] also focused on technology mergers and acquisitions and independent research and development and conducted a comparative study on the role of these two factors in promoting the overall economic growth of China from 2001 to 2015. The results of the research mentioned before indicate the role of technology mergers and acquisitions is substantial.

Overall, numerous researchers have compared the effect of independent research and development and technology mergers and acquisitions on regional economic development and business development by using various analytical approaches. However, prior studies rarely involved the mechanism of independent research and development and technology mergers and acquisitions strategic decisionmaking. In other words, they neglected how to choose and coordinate between independent research and development and technology mergers and acquisitions. In addition, there is a lack of relevant research to assist companies in deciding research and development strategies.

As a result, this research has three research objectives: (1) to explore the chief factors that influence the two research and development decisions of independent research and development and technology mergers and acquisitions; (2) to construct a duopoly enterprise game model under the condition of complete information and, from the perspective of equilibrium profits, to explore the advantages and decisionmaking mechanisms of independent research and development and technology mergers and acquisitions; (3) in the context of the actual development of Chinese companies, to inform suitable research and development decisions and provide credible theoretical and practical support for the choice of research and development strategies.

In this paper, this research (1) takes corporate research and development decision-making as the unit of analysis, (2) uses independent research and development and technology mergers and acquisitions decision-making as a breakthrough point, (3) refers to relevant literature to analyze and compare the decision-making mechanism of independent research and development and technology mergers and acquisitions, (4) deepens research on the mechanism of research and development strategy's influence on technology accumulation and technology progress, and (5) provides theoretical and practical support for companies to choose the most suitable research and development strategy.

Specifically, considering the two stages of research and development and production, this research introduces the three variables of spillover effect, cost of merger and acquisition, and research and development efficiency to establish a dynamic game model of research and development decision. This research uses these variables to establish a balanced profit expression between independent research and development and technology mergers and acquisitions, examining the choice and coordination between independent research and development and technology mergers and acquisitions strategies, exploring the influence of various factors on research and development strategy decision, and providing a theoretical basis for research and development strategy decisions.

\section{The Decision-Making Process of Research and Development Strategies}

2.1. General Steps of the Research and Development Strategy Decision. From the perspective of the decision-making process of research and development strategies, the company analyzes and compares each research and development model in terms of maximum benefit, maximum cost reduction, and responsiveness to knowledge [19].

2.1.1. Forecast the Maximum Profit under Each Research and Development Model. When making research and development decisions, it is necessary to select the research and development mode. At this time, not only internal factors, such as the maximum profit and the learning ability capacity, but also external factors, such as technology spillover, market structure, and market competition, must be considered. To establish a comparative analysis, this research uses the maximum equilibrium profit to measure the maximum profit of various research and development modes.

2.1.2. Choose a Research and Development Model that Maximizes Profits. Many factors influence the choice of the research and development model. Under normal circumstances, when companies choose independent research and development or technology mergers and acquisitions, the first consideration is to maximize research and development profits. Therefore, after predicting the maximum profits of both research and development models, it is necessary to compare and analyze both and select the one that generates the greatest amount of profit [20]. Since the maximum profit from $\mathrm{R} \& \mathrm{D}$ is linked to spillover effects, research productivity, and acquisitions and mergers costs, choosing an R\&D model should consider these factors.

\subsection{Identify the Influencing Factors of Research and Development Strategy Decisions}

2.2.1. Spillover Effect. The spillover effect is a significant factor that affects research and development decisions [21]. The spillover effect is formed by the externality of knowledge, which facilitates the transfer and diffusion of current knowledge to other companies. By contrast, the current knowledge not only is used in the R\&D process but also generates other current knowledge borrowed and imitated by other companies. The spillover effect may increase profit and the technology innovation ability. However, the process may harm companies that engage in research and development as other companies profit from the knowledge.

Knowledge can be obtained not only from research and development but also from other companies through learning as knowledge is reproducible. Hence, some companies may save human resources, physical resources, and financial resources and thus make a profit. 
2.2.2. Research and Development Efficiency. The model of research and development investment concerns the organizational strategy of research and development activities. Steensma and Fairbank [22] divided research and development investment into four components: internal research and development, research and development alliance, mergers and acquisitions, and technology purchase. Diverse research and development models have variable effects on research and development speed, research and development risk, cost, and difficulty of use. Therefore, when facing diverse market environments and diverse objectives, companies should make choices based on current conditions.

Research and development efficiency is a significant factor for the research and development decisions of independent research and development and technology mergers and acquisitions. Independent research and development refers to the use of own resources and knowledge reserves to conduct research and development. This research and development mode relies on the company's unique resources and advantages, whose research and development results are exclusive and can be used and exploited. However, independent research and development fail to affect the organizational ability to absorb and acquire external knowledge. Like independent research and development, mergers and acquisitions are actions that companies take to gain control and ownership of other companies' resources. Technology mergers and acquisitions can help companies acquire modern knowledge and technology faster and penetrate the market faster to expand their market share. Therefore, corporate research and development efficiency may have an impact on the choice of corporate research and development model. High research and development efficiency lowers the investment in independent research and development and increases profits, while low research and development efficiency not only consumes too many resources but also introduces continuous risk to the company [23].

2.2.3. Cost of Mergers and Acquisitions. Technology mergers and acquisitions differ from commodities trading activities in that they are used to trade the capital assets of enterprises. However, in essence, mergers and acquisitions are still a special kind of commodity trading activity, which is property rights transactions to gain control and ownership of assets from other companies under the extant market mechanism [24]. The costs of mergers and acquisitions include purchase and integration costs. Higher costs of mergers and acquisitions increase the company's research and development investment. Economic theory informs us that whether the usual commodity transaction activities can be carried out depends on whether the transaction costs can meet the company's consideration indicators. Therefore, the cost of mergers and acquisitions is a factor that affects decision-making choices, and it is also the theoretical cornerstone for us to analyze the motivation of technology mergers and acquisitions from a cost perspective.

The complexity of technology mergers and acquisitions itself also determines the cost of mergers and acquisitions.
The composition of modern corporate costs of mergers and acquisitions includes financing procurement costs, tax costs, system costs, capital costs, and intermediate costs. The ultimate objective of corporate mergers and acquisitions is to increase the postmerger valuation of the company. As long as mergers and acquisitions are conducive to the growth of corporate value, it is feasible in principle. Therefore, it is not challenging for companies to make mergers and acquisitions decisions. However, acquisition costs complicate the decision-making process. Companies must make the appropriate balance between acquisition revenue and acquisition costs to ensure that net acquisition income is positive. In addition, if the acquisition costs are too high to implement the acquisition based on the current strength of the acquirer, then the best strategy for the acquirer is to abandon the acquisition.

Costs are the basis for companies to make technology mergers and acquisitions decisions. If you ignore the cost calculation, it greatly increases the risk of technology mergers and acquisitions. Increasing the price of technology mergers and acquisitions results in increased burdens and reduced income, which in turn hurts merger expectations. Gao [25] pointed out that when multinational companies choose mergers and acquisitions target locations in China, the cost of mergers and acquisitions should be considered as a factor. Such mergers and acquisitions activities will have an impact on regional economic and social development. Therefore, organizations and governments actively take various measures to reduce costs.

\section{Model Assumption}

3.1. Model Assumption. Research and development decision-making involves uncertainty such as technology proliferation, risky behavior, decision-making adaptability, and environmental complexity [26]. This research aims to provide a better perspective for research and development decision-making based on the basic theories of independent research and development and technology mergers and acquisitions as well as extant cutting-edge and classic literature, fully considering the decision-making process of research and development strategies and combining the characteristics of the two-stage dynamic game model to establish a two-stage game for the research and development decision model.

Regarding the research and development investment, cost reduction and market expansion (or sales improvement) are the two chief objectives [27]. This research draws on the two-stage investment-defense game analysis of balancing strategy and operational decision-making [28] and proposes the following assumptions for the game process of independent research and development and technology mergers and acquisitions: (1) there are only two companies in the model; (2) the level of technology spillover is an exogenous variable; (3) the marginal costs of the two companies are not only the same but also symmetrical; (4) to maximize profits, the equilibrium cost of their unit products is reduced, which is why research and development modes exist; and (5) according to Ge et al. [29], research and 
development effort (or R\&D input) is quadratic in terms of cost reduction. Specifically, the assumption is as follows.

Assumption 1. Suppose that there are two companies $(i, j)$ producing the same product in a certain industry and $p$ is the price. $q_{i}$ and $q_{j}$ represent the output of companies $i$ and $j$, respectively, where $a>0$ and $b>0$ are the demand curve parameters, assuming that the inverse demand function is

$$
p=a-b\left(q_{i}+q_{j}\right)
$$

Assumption 2. Set $x_{i}$ as the product cost reduction rate; $\beta(0 \leq \beta \leq 1)$ is the level of technology spillover. The independent research and development investment of the company itself and the technology transfer of another company due to technology spillovers are beneficial to reducing the effective product cost. The effective cost reduction of enterprise $i$ is

$$
X_{i}=x_{i}+\beta x_{j}
$$

Assumption 3. Assuming that the change of research and development investment only has an impact on the unit cost of the company and the two companies have the same initial unit cost $c(0<c<a)$ and furthermore assuming that there is no fixed cost, this research uses $\left(c-X_{i}\right)$ to represent the marginal cost after the company adjusts the research and development investment to reduce the unit cost. The cost function can be expressed as follows:

$$
c_{i}=c-X_{i}=c-x_{i}-\beta x_{j}
$$

Assumption 4. The research and development investment of company $i$ is $y_{i}$. The research and development investment follows the law of diminishing marginal return, so $x_{i}$ appears in quadratic form in the total cost function; then, the research and development investment of the company can be expressed as follows:

Independent research and development:

$$
y_{i}=\frac{1}{2} \rho x_{i}^{2}
$$

Technology mergers and acquisitions:

$$
y_{i}=\frac{1}{2} \rho\left(x_{i}^{2}+\delta x_{j}^{2}\right) .
$$

The value of the coefficient ${ }_{\rho}$ reflects research and development efficiency. When the innovation results are the same, the smaller the value of $y_{i}$, the lower the research and development cost, so the higher the research and development efficiency. $\delta$ represents the cost of transferring technology and knowledge through mergers and acquisitions and meets the requirement of $\delta>0$.

This research proposes a two-stage game model. The first stage is the research and development investment stage, which means that the company chooses the most suitable research and development investment level $y_{i}$ under the condition of unit product cost reduction. The second stage is the output decision stage. The two companies compete in the market to maximize profits and choose the corresponding output $q_{i}$.

The whole process is a complete information two-stage game. In the first stage (research and development investment stage), there is a subgame perfect Nash equilibrium. In the first stage, companies expect an impact of their decision on profit in the second stage. The model is solved employing backward induction.

\subsection{Model Establishment}

3.2.1. Phase II (Output Phase). Both companies, whether they choose independent research and development or technology mergers and acquisitions, independently set output in the output phase. After setting the output, the two companies compete in the product market. According to the previous assumptions, the profit function of company $i$ is as follows:

Independent research and development:

$$
\begin{aligned}
\pi_{i} & =\left(p-c_{i}\right) q_{i}-y_{i} \\
& =\left[a-b\left(q_{i}+q_{j}\right)-\left(c-x_{i}-\beta x_{j}\right)\right] q_{i}-\frac{1}{2} \rho x_{i}^{2} .
\end{aligned}
$$

Technology mergers and acquisitions:

$$
\begin{aligned}
\pi_{i} & =\left(p-c_{i}\right) q_{i}-y_{i} \\
& =\left[a-b\left(q_{i}+q_{j}\right)-\left(c-x_{i}-\beta x_{j}\right)\right] q_{i}-\frac{1}{2} \rho\left(x_{i}^{2}+\delta x_{j}^{2}\right) .
\end{aligned}
$$

In the case of a given research and development investment, when the company's equilibrium profit is maximized, the conditions of $\left(\partial \pi_{i} / \partial q_{i}\right)=0$ and $\left(\partial^{2} \pi_{i} / \partial q_{i}^{2}\right)<0$ should be satisfied, and the Cournot equilibrium output of the second stage can be obtained as

$$
q_{i}^{*}=\frac{a-c+(2-\beta) x_{i}+(2 \beta-1) x_{j}}{3 b} .
$$

Bring (4)-(7) into (4)-(6) and this research can obtain the following:

Independent research and development:

$$
\pi_{i}=\frac{1}{9 b}\left[(a-c)+(2-\beta) x_{i}+(2 \beta-1) x_{j}\right]^{2}-\frac{1}{2} \rho x_{i}^{2} .
$$

Technology mergers and acquisitions:

$$
\pi_{i}=\frac{1}{9 b}\left[(a-c)+(2-\beta) x_{i}+(2 \beta-1) x_{j}\right]^{2}-\frac{1}{2} \rho\left(x_{i}^{2}+\delta x_{j}^{2}\right) .
$$

\subsubsection{Phase I (Independent Research and Development).} The type of research and development model leads to different profit outcomes. 
(1) Independent Research and Development. If the research and development investment levels of other companies are known, the two companies first independently establish their research and development investment decisions. The two companies seek cost reductions $x_{i}$ and independent research and development investment $y_{i}$ to maximize profit. That is, $\pi_{R}=\max _{x_{i}}$ $\pi_{i}$, and its equilibrium is determined by $\pi_{i}$. Because of the symmetry of the initial unit costs of the two companies, this research solved the first-order condition $\left(\partial \pi_{i} / \partial x_{i}\right)=0$ and obtained the Nash equilibrium result as follows:

$$
x_{i}^{*}=\frac{(a-c)(2-\beta)}{4.5 b \rho-(2-\beta)(1+\beta)} .
$$

Substitute (11) into (9) to obtain profit as

$$
\pi_{R}=\frac{\rho(a-c)^{2}\left[4.5 b \rho-(2-\beta)^{2}\right]}{2[4.5 b \rho-(2-\beta)(1+\beta)]^{2}} .
$$

(2) Technology Mergers and Acquisitions. Technology mergers and acquisitions are not only the fastest and most effective research and development strategy for companies but also the most efficient method for companies to acquire innovation. In the research and development model of mergers and acquisitions, $\beta=1$. Due to the symmetry of the initial costs, the company's profit function is

$$
\pi_{A}=\frac{1}{9 b}\left[(a-c)+x_{i}+x_{j}\right]^{2}-\frac{1}{2} \rho\left(x_{i}^{2}+\delta x_{j}^{2}\right) .
$$

Similarly, the company maximizes profit employing cost reductions $x_{i}$ and its equilibrium is determined by $\max _{x_{i}} \pi_{A}$. By solving the first-order condition $\left(\partial \pi_{A} / \partial x_{i}\right)=0$, this research knows that the equilibrium result is

$$
x_{i}^{*}=\frac{a-c}{4.5 b \rho-2} .
$$

Substitute (14) into (13) to obtain profit as

$$
\pi_{A}=\frac{\rho(a-c)^{2}[4.5 b \rho-(\delta+1)]}{2(4.5 b \rho-2)^{2}} .
$$

\section{Model Analysis}

Company $i$ can obtain spillover effects from enterprise $j$. At the same time, company $j$ can also obtain spillover effects from company $i$. Therefore, the spillover effect represents a double-edged sword from the perspective of the company $i$. If a larger spillover effect occurs, company $i$ can obtain a larger spillover effect from company $j$ and therefore enhance its competitiveness. However, company $i$ will also have a larger spillover effect, therefore giving company $j$ a certain advantage and weakening its competitive advantage. Therefore, when analyzing the impact of changes in spillover effects on company $i$, it must be viewed from two aspects.

When $0 \leq \beta \leq 1,4.5 b \rho-(2-\beta)^{2}$ is the increasing function of $\beta$; when $0 \leq \beta \leq 0.5,4.5 b \rho-(2-\beta)(1+\beta)$ is the decreasing function of $\beta$; and when $0.5 \leq \beta \leq 1,4.5 b \rho-(2-$ $\beta)(1+\beta)$ is the increasing function of $\beta$. Therefore, when
$0.5 \leq \beta \leq 1, \pi_{R}(\beta)$ takes the maximum value at $\beta=0.5$; when $0.5 \leq \beta \leq 1, \pi_{R}(\beta)$ takes the maximum value depending on the value of parameter $4.5 b \rho$ :

$$
\frac{\mathrm{d} \pi_{R}}{\mathrm{~d} \beta}=\frac{\rho(a-c)^{2}\left[3(1-\beta)(4.5 b \rho)-(2-\beta)^{3}\right]}{[4.5 b \rho-(2-\beta)(1+\beta)]^{3}} .
$$

Therefore, the spillover effect $\beta^{*}$ that maximizes the profit from company $i$ should satisfy the condition $3\left(1-\beta^{*}\right)(4.5 b \rho)-\left(2-\beta^{*}\right)^{3}=0$. When $\beta=1$, $\left(\mathrm{d} \pi_{R} / \mathrm{d} \beta\right)<0$, therefore $\beta^{*}<1$; when $\beta=0.5$, there is $3(1-\beta)(4.5 b \rho)-(2-\beta)^{3}=1.5\left[4.5 b \rho-(2-\beta)^{2}\right]>0$, so $\beta^{*}>0.5$. In summary, $0.5<\beta^{*}<1$. Substitute $\beta=0$ and $\beta=1$ into $\pi_{R}(\beta)$, respectively, and this research can obtain that $\pi_{R}(0)=\left(\rho(a-c)^{2}[4.5 b \rho-4] / 2[4.5 b \rho-2]^{2}\right)<\pi_{R}(1)=(\rho$ $\left.(a-c)^{2}[4.5 b \rho-1] / 2[4.5 b \rho-2]^{2}\right)$, and the minimum value of $\pi_{R}(\beta)$ is $\beta=0$. From (4)-(15), this research can obtain that $\delta$ is the decreasing function of $\pi_{A}(\delta)$, assuming $\pi_{R}>0, \pi_{A}>0$. When $\delta>3, b \rho>(2(\delta+1) / 9)$ is required and $\pi_{A}(\delta)<\pi_{R}(0)_{\min }=\left(\rho(a-c)^{2}[4.5 b \rho-4] / 2[4.5 b \rho-2]^{2}\right)$ is satisfied. When $0<\delta<3, \rho b>(8 / 9)$ is required. There is $\bar{\beta}$, so that $\pi_{A}(0)_{\max }=\pi_{R}(\bar{\beta})=\pi_{R}(1)$. When $0<\beta \leq \bar{\beta}$, this research could always find that $\pi_{A}(\delta)=\pi_{R}(\beta)$. When $\bar{\beta}<\beta \leq 1, \pi_{A}(\delta)<\pi_{R}(\beta)$.

Proposition 1. When $\delta>3$, because $\pi_{R}>0, \pi_{A}>0$, the condition $b \rho>(2(\delta+1) / 9)$ is required. No matter what value $\beta$ takes in $[0,1]$, there is always $\pi_{A}(\delta)<\pi_{R}(\beta)$. That is, the profit of independent research and development is greater than mergers and acquisitions, and independent research and development is chosen.

In mergers and acquisitions, the merged companies should be responsible for the sum of the costs incurred in merging. These costs relate not only to mergers and acquisitions but also to the integration of various resources after the merger is complete; the sum of these costs includes both the tangible costs that are visible and the intangible costs that are not visible in mergers and acquisitions. That is, excessive costs of mergers and acquisitions increase the research and development investment and the tangible and intangible burden of the company. Consequently, profits from mergers and acquisitions also decline, negatively affecting the activity of mergers and acquisitions. Therefore, when the costs of mergers and acquisitions are higher to a certain degree, companies will relinquish mergers and acquisitions and choose independent research and development instead.

Proposition 2. When $0<\delta<3$, because $\pi_{R}>0, \pi_{A}>0$, $\rho b>(8 / 9)$ is required. When $0<\beta \leq \bar{\beta}$, this research can always find that $\pi_{A}(\delta)=\pi_{R}(\beta)$. That is, you can choose both independent research and development and mergers and acquisitions. When $\bar{\beta}<\beta \leq 1, \pi_{A}(\delta)<\pi_{R}(\beta)$. The profit from independent research and development is greater than that of mergers and acquisitions, and independent research and development are chosen.

In other words, a higher spillover effect reduces the costs of independent research and development, which increases 
TABLE 1: The profit $\pi_{R}$ under independent research and development strategy.

\begin{tabular}{lcccccc}
\hline$\rho$ & \multicolumn{5}{c}{$\beta$} \\
\hline 0.0 & 0.0 & 0.2 & 0.4 & 0.6 & 0.8 & 1.0 \\
0.1 & -0.13 & -0.07 & -0.05 & -0.03 & -0.02 & 0.00 \\
0.2 & -5.50 & -1.11 & -0.39 & -0.08 & 0.28 & 2.00 \\
0.3 & -0.40 & -0.28 & 0.10 & 0.53 & 0.65 & 0.52 \\
0.4 & -0.03 & 0.04 & 0.11 & 0.18 & 0.21 & 0.20 \\
0.5 & 0.02 & 0.06 & 0.10 & 0.12 & 0.14 & 0.14 \\
0.6 & 0.04 & 0.06 & 0.09 & 0.10 & 0.11 & 0.11 \\
0.7 & 0.04 & 0.06 & 0.08 & 0.09 & 0.10 & 0.10 \\
0.8 & 0.05 & 0.06 & 0.08 & 0.09 & 0.09 & 0.09 \\
0.9 & 0.05 & 0.06 & 0.07 & 0.08 & 0.09 & 0.09 \\
1.0 & 0.05 & 0.06 & 0.07 & 0.08 & 0.08 & 0.08 \\
\hline
\end{tabular}

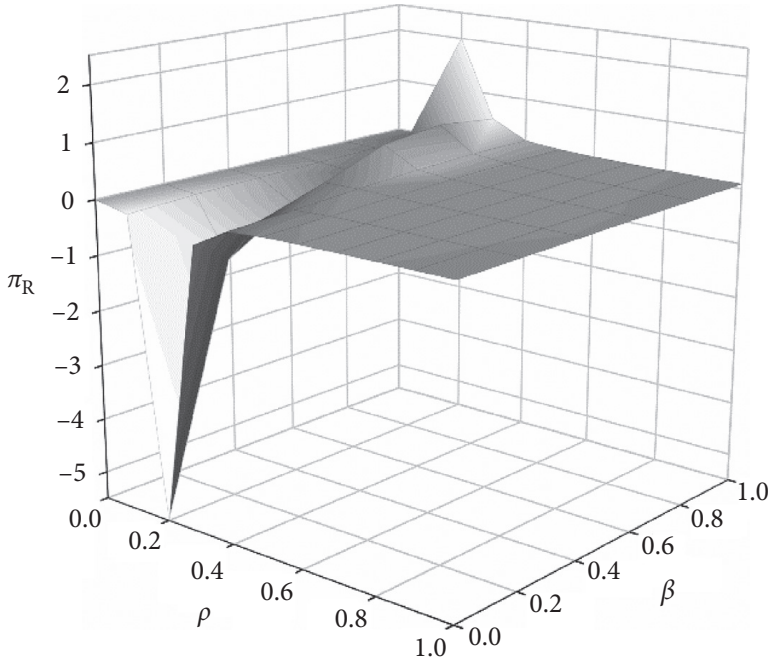

Figure 1: The profit $\pi_{R}$ under independent research and development strategy.

TABle 2: The profit $\pi_{A}$ under mergers and acquisitions strategy.

\begin{tabular}{lcccccc}
\hline$\rho$ & \multicolumn{7}{c}{$\delta$} \\
& 0.0 & 2.0 & 3.0 & 5.0 & 7.0 & 9.0 \\
\hline 0.0 & 0.00 & 0.00 & 0.00 & 0.00 & 0.00 & 0.00 \\
0.1 & 0.00 & -0.09 & -0.13 & -0.21 & -0.29 & -0.38 \\
0.2 & 2.00 & -3.00 & -5.50 & -10.50 & -15.50 & -20.50 \\
0.3 & 0.52 & -0.09 & -0.40 & -1.01 & -1.62 & -2.24 \\
0.4 & 0.20 & 0.05 & -0.03 & -0.19 & -0.34 & -0.50 \\
0.5 & 0.14 & 0.06 & 0.02 & -0.06 & -0.14 & -0.22 \\
0.6 & 0.11 & 0.06 & 0.04 & -0.02 & -0.07 & -0.12 \\
0.7 & 0.10 & 0.06 & 0.04 & 0.01 & -0.03 & -0.07 \\
\hline
\end{tabular}

the profit. Therefore, when the costs of mergers and acquisitions are certain, a higher spillover effect helps independent research and development.

\section{Numerical Simulation and Analysis}

Suppose there are only two companies in the market and the duopolies are symmetrical. Suppose $a=2, b=2$, and $c=1$. This research inserts the two companies into the previous

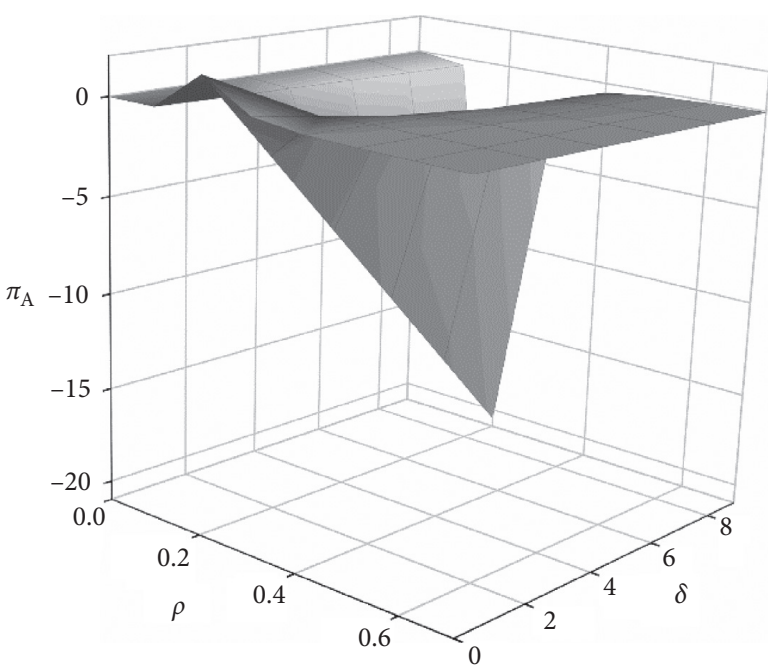

FIgURE 2: The profit $\pi_{A}$ under mergers and acquisitions strategy.

model to get the profits of independent research and development and mergers and acquisitions. The profit from independent research and development is shown in Table 1 and illustrated in Figure 1. As can be seen from Table 1, the profit $\pi_{R}$ of independent research and development increases first and then decreases as the spillover effect $\beta$ increases. When $\beta=0, \pi_{R}$ takes the minimum value.

The profit from mergers and acquisitions is shown in Table 2 and illustrated in Figure 2. Table 2 shows how the profit $\pi_{A}$ of mergers and acquisitions is gradually reduced as the cost of mergers and acquisitions $\delta$ increases. When the cost of mergers and acquisitions is $\delta=3, \pi_{R}(0)_{\min }=\pi_{A}(3)$.

Therefore, when $\delta>3, \pi_{R}>\pi_{A}$. That is, the profit from independent research and development is greater than that of mergers and acquisitions, and independent research and development are subsequently chosen. When $0<\delta<3$, this research observes that $\pi_{A}(3)_{\min }=\pi_{R}(0)_{\min }$ and $\pi_{A}(0)_{\max }=\pi_{R}(\bar{\beta})=\pi_{R}(1)$. Therefore, when $0<\beta \leq \bar{\beta}$, $\pi_{A}(\delta)=\pi_{R}(\beta)$ can always be found. That is, companies can choose independent research and development and mergers and acquisitions. When $\bar{\beta}<\beta \leq 1, \pi_{A}(\delta)<\pi_{R}(\beta)$. That is, the profit associated with independent research and development is greater than mergers and acquisitions, and independent research and development are chosen.

\section{Summary and Conclusion}

This research utilized game theory and selected three variables of spillover effect, research and development efficiency, and cost of mergers and acquisitions to establish a duopoly model. This research utilized the three variables to establish the equilibrium profit expression of independent research and development and technology mergers and acquisitions. This research explored the problem at the two stages of research and development investment and production quantity with an objective of profit maximization. Based on simulations, our results show that if the cost of technology mergers and acquisitions is high, the incentive to invest in research and development increases, and the 
incentive to engage in mergers and acquisitions activity decreases. The complexity of the research and development strategy decision-making process is further increased by the objectivity of the cost of mergers and acquisitions. After weighing the benefits and costs, companies must establish the right choice between internal research and development and technology mergers and acquisitions. Therefore, when the cost of mergers and acquisitions reaches or exceeds a certain level, technology mergers and acquisitions are abandoned in favor of independent research and development. The spillover effect is formed by the externality of knowledge, which implies the continuous transfer and diffusion of current knowledge. Consequently, companies utilize knowledge to profit and reinvest in technology innovation ability. A higher spillover effect reduces the cost of independent research and development, which facilitates higher profits. Therefore, with a certain cost of mergers and acquisitions, a higher spillover effect helps independent research and development.

This research comes up with the following conclusions: (1) excessive costs of mergers and acquisitions increase the tangible and intangible burdens of enterprises, weaken the benefits of mergers and acquisitions, and have a profound negative impact on the company's mergers and acquisitions expectations. Therefore, when the cost of mergers and acquisitions is higher to a certain level, enterprises will relinquish mergers and acquisitions and choose independent research and development instead. (2) The spillover effect facilitates the continuous transfer and diffusion of current knowledge to other companies, therefore causing an improvement in profit and technology innovation ability and a cost reduction. A higher spillover effect reduces the cost of independent research and development by an enormous degree, which facilitates higher profits. Therefore, with a certain cost of mergers and acquisitions, a higher spillover effect improves the prospect of independent research and development.

Under the premise of a static game, this research conducts a game theory analysis of the choice of independent research and development and technology mergers and acquisitions, but this research does not discuss how incomplete information and dynamic games affect the choice of research and development mode. In consideration of the research and development decision-making process, this research considers the three variables of spillover effect, research and development efficiency, and cost of mergers and acquisitions. The analysis of these three variables to the choice between internal research and development and technology mergers and acquisitions is qualitative. Future research should address the quantification of these three variables to facilitate better inferences of the model. The present study is theoretical. This research looks forward to applied research endeavors to inform if the model can explain or predict behavior in practice.

Finally, the limitations of this research failed to explain the time of this game theory. In most game theory models, the relentlessly random nature of the real world is not reflected, but that is not how it is. Competition can be influenced by the timing and type of information a company receives, so that is why timing is important in decisionmaking a decision. Grana and his collaborators [30] examined what happens when players receive information or act at unpredictable times, as determined via continuoustime evolution, which shows a current direction of research in game theory. Consequently, we need to explain the time frame for this game theory in the future.

\section{Data Availability}

The data used to support the findings of this study are included within the article.

\section{Conflicts of Interest}

The authors declare that they have no conflicts of interest.

\section{Acknowledgments}

This research was supported by the Humanities and Social Sciences Project of the Ministry of Education (21YJC630130), Youth Project of Natural Science Foundation of Anhui Province (2008085QG346), Anhui Philosophy and Social Sciences Planning Project (AHSKY2019D022), Anhui Province 2020 Excellent Talents Cultivation Project (gxgwfx2020006), and "Six Excellence and One Top-Notch" Excellent Talent Training Innovation Project of Anhui Province (2020zyrc035).

\section{References}

[1] H. Zhu and C. Zhuang, "Research on the performance of corporate technology mergers and acquisitions based on synergies-taking listed companies as an example," Soft Science, vol. 30, no. 07, pp. 58-61+69, 2016.

[2] L. Yang, "Influence of technology import and independent $\mathrm{R} \& \mathrm{D}$ on economic growth-a study based on the perspective of intellectual property protection," Science Research Management, vol. 41, no. 06, pp. 9-16, 2020.

[3] L. Wu and G. Cao, "Research on R\&D investment decision making under uncertainty of technology and price," Systems Engineering-Theory \& Practice, vol. 37, no. 7, pp. 1720-1726, 2017.

[4] X. Sun, X. Liu, Y. Wang, and Y. Bai, "Whether to invest and how much will invest: the two stages decision of firm $R \& D$ investment," Journal of Industrial Engineering and Engineering Management, vol. 31, no. 4, pp. 85-92, 2017.

[5] L. M. Cortés, I. A. Durán, S. Gaitán, and M. Vasco, "Mergers and acquisitions in latin America: industrial productivity and corporate governance," Emerging Markets Finance and Trade, vol. 53, no. 10, pp. 2179-2198, 2017.

[6] Y. Hau, "The effect of the exterior R\&D network on the import substitution of small and medium venture firms: the moderating impact of corporate R\&D center," Journal of Digital Convergence, vol. 15, no. 11, pp. 199-207, 2017.

[7] X. Zhao, D. Lin, and T. Hao, "A new discussion on the relationship between M\&A and innovation in an emerging market: the moderating effect of post-acquisition R\&D investment," Technology Analysis \& Strategic Management, vol. 31, no. 12, pp. 1447-1461, 2019.

[8] Y. He, Q. Han, and Y. Zeng, "A research on the impact of indigenous innovation on the international competitiveness 
of China's manufacturing industry," Science Research Management, vol. 40, no. 07, pp. 33-46, 2019.

[9] J. Wei, D. Wang, and Y. Liu, "Disadvantages of original country and legitimacy strategies: case studies on EMNEs' cross-border M\&A," Management World, vol. 36, no. 03, pp. 101-120, 2020.

[10] X. Cao, X. Yang, and L. Zhang, "Threshold effect of technical distance: independent R\&D and collaborative innovation," Studies in Science of Science, vol. 38, no. 03, pp. 536-544, 2020.

[11] X. Li and G. Wu, "In-house R\&D, technology purchase and innovation: empirical evidences from Chinese hi-tech industries, 1995-2004," International Journal of Technology Management, vol. 51, no. 2-4, pp. 217-238, 2010.

[12] K. H. Kang, G. S. Jo, and J. Kang, "External technology acquisition: a double-edged sword," Asian Journal of Technology Innovation, vol. 23, no. 1, pp. 35-52, 2015.

[13] R. Bai and S. Tan, "R\&D mode, vertical integration and innovation performance of indigenous brand in the introduction period," Journal of Management Science, vol. 29, no. 04, pp. 70-79, 2016.

[14] D. Wang and B. Han, "Effects of indigenous R\&D and foreign spillover on energy intensity in China," Journal of Renewable and Sustainable Energy, vol. 9, no. 3, 2017.

[15] C. Du, J. Lv, and M. Rui, "The research on the relationship between enterprise's technology importing and independent R\&D in industry upgrading," Scientific Management Research, vol. 36, no. 4, pp. 51-55, 2018.

[16] L. Liu and X. Liu, "Indigenous R\&D, technology import and domestic technological content of the manufacturing industry," Science Research Management, vol. 39, no. 8, pp. 34-42, 2018.

[17] Q. Yue, X. Hua, and J. Li, "Internal R\&D and acquisition performance of Chinese pharmaceutical firms: moderation effect of acquisition motive and corporate ownership," Processes, vol. 7, no. 5, p. 292, 2019.

[18] R. Zhang and B. Sun, "A competitive dynamics perspective on evolutionary game theory, agent-based modeling, and innovation in high-tech firms," Management Decision, vol. 58, no. 12, pp. 948-966, 2019.

[19] R. L. Bray, "Markov decision processes with exogenous variables," Management Science, vol. 65, no. 10, pp. 4598-4606, 2019.

[20] Z. Zhu, J. Peng, K. Liu, and X. Zhang, "A game-based resource pricing and allocation mechanism for profit maximization in cloud computing," Soft Computing, vol. 24, no. 6, pp. 4191-4203, 2020

[21] C. Zhou, N. Ma, X. Cui, and Z. Liu, "The impact of online referral on brand market strategies with consumer search and spillover effect," Soft Computing, vol. 24, no. 4, pp. 2551-2565, 2020.

[22] H. K. Steensma and J. F. Fairbank, "Internalizing external technology: a model of governance mode choice and an empirical assessment," The Journal of High Technology Management Research, vol. 10, no. 1, pp. 1-35, 1999.

[23] T. Hong and B. Li, "Measurement and division of research and development efficiency of listed agricultural enterprises in China-empirical analysis based on SBM-Malmquist model and enterprise life cycle," Inquiry into Economic Issues, vol. 41, no. 9, pp. 65-77, 2020.

[24] H. Sharanlou, A. Husseinzadeh Kashan, and R. TavakkoliMoghaddam, "Determining the price and refund of products in a supply chain with quality and advertising costs in a fuzzy environment," Soft Computing, vol. 25, no. 1, 2021.
[25] M. Gao, "On location choice of China's inward cross-border mergers and acquisitions and its impact on regional economic development," Master thesis, Wuhan University of Technology, Wuhan, China, 2006.

[26] B. Han, Y. Su, T. Li, and M. Wan, "Technological innovation performance of high-tech enterprises based on two-stage DEA model," Science Research Management, vol. 39, no. 3, pp. 11-19, 2018.

[27] R. Belderbos, M. Carree, and B. Lokshin, "Cooperative R\&D and firm performance," Research Policy, vol. 33, no. 10, pp. 1477-1492, 2004.

[28] A. Yolmeh and M. Baykal-Gürsoy, "Two-stage invest-defend game: balancing strategic and operational decisions," Decision Analysis, vol. 16, no. 1, pp. 46-66, 2019.

[29] Z. Ge, Q. Hu, and Y. Xia, "Firms' R\&D cooperation behavior in a supply chain," Production and Operations Management, vol. 23, no. 4, pp. 599-609, 2014.

[30] J. Grana, J. Bono, and D. Wolpert, "Reasoning about "when" instead of "what": collusive equilibria with stochastic timing in repeated oligopoly," The B.E. Journal of Theoretical Economics, vol. 20, no. 1, 2020. 